\title{
Ab initio study in the hydration process of metaphosphoric acid: the importance of the pnictogen interactions
}

\author{
Ibon Alkorta $\cdot$ Luis Miguel Azofra $\cdot$ José Elguero
}

Received: 16 December 2014 / Accepted: 28 January 2015 / Published online: 13 February 2015

(C) Springer-Verlag Berlin Heidelberg 2015

\begin{abstract}
A theoretical study of the hydration of metaphosphoric acid to yield phosphoric acid has been carried out by means of $\mathrm{MP} 2 / 6-31+\mathrm{G}(d, p)$ and MP2/augcc-pVTZ computational levels. Up to three explicit water molecules have been considered as well as the PCM solvation model to account for the effect of the bulk water. The reaction profile has been analyzed using the conceptual DFT methodology. The reactant structure is very dependent on the number of water molecules. The inclusion of more than one water molecule produces important cooperative effects and a shortening of the O...P pnictogen interaction besides the reaction barrier drops about $50 \mathrm{~kJ} \mathrm{~mol}^{-1}$. Reaction force at $\xi_{1}$ indicates the decreasing in the angular stress in the reaction site before reaching the TS as more explicit water molecules are taken into account. The analysis of the reaction electronic flux shows that for the three mechanisms studied, the principal reactive changes occur in the TS zone, while reactants and products remain in a zero-flux regime.
\end{abstract}

Keywords $\mathrm{HPO}_{3} \cdot$ Chemical reactivity $\cdot$ Noncovalent interactions $\cdot \mathrm{CDFT} \cdot \mathrm{MP} 2$

\section{Introduction}

Hydration reaction, that is, the addition of water or its elements (i.e., $\mathrm{H}$ and $\mathrm{OH}$ ) to a molecular entity, is one of the most important chemical processes [1]. Besides, it is well

I. Alkorta $\cdot$ L. M. Azofra $(\varangle) \cdot$ J. Elguero

Instituto de Química Médica, CSIC, Juan de la Cierva, 3,

E-28006 Madrid, Spain

e-mail: luisazofra@iqm.csic.es known that the inorganic phosphorus oxoacids are one of the many systems which experiment such reaction (and its reverse one, dehydration) when transformed in the different oxoacid species.

In the present paper, our efforts were concentrated on the study of the hydration reaction of metaphosphoric acid $\left(\mathrm{HPO}_{3}\right)$, a water- or moisture-absorbing reagent that, upon water absorption, evolves to orthophosphoric, also known as phosphoric acid $\left(\mathrm{H}_{3} \mathrm{PO}_{4}\right)$. The dehydration of $\mathrm{H}_{3} \mathrm{PO}_{4}$ to $\mathrm{HPO}_{3}$ in aqueous solution has been measured experimentally as $134 \pm 8 \mathrm{~kJ} \mathrm{~mol}^{-1}$ [2]. Also, dehydration of the protonated phosphoric acid has been studied theoretically, and the proton affinity of $\mathrm{HPO}_{3}$ has been calculated to be $712 \mathrm{~kJ} \mathrm{~mol}^{-1}$ at the G2(MP2) computational level [3]. In addition, hydrolysis of different phosphorus derivatives as phosphate anion [4], phosphate monoesters [5] and phosphate diesters and triesters [6] has been studied computationally. The protonation and dehydration of the protonated form of orthophosphoric acid have been studied experimentally and theoretically [3]. Finally, in 2002, Davies et al. estimated the $\mathrm{p} K_{\mathrm{a}}$ values of pentaoxyphosphoranes based on single bonds lengths [7], and more recently, the study of pnictogen (or pnicogen)-bonded complexes of the related $\mathrm{PO}_{2} \mathrm{X}(\mathrm{X}=\mathrm{F}, \mathrm{Cl}$ and $\mathrm{Br})$ compounds with electron donors reveals the great power of $P$ as electron acceptor $[8,9]$.

In the present work, we will analyze the reaction mechanism of the hydration of metaphosphoric acid, focusing on the key role the number of explicit water molecules play as reactants or bridges in the assistance of the proton transfer, as well as the importance of the pnictogen interactions [1, 8-23], which are noncovalent forces [24] of electrostatic nature which favor bounded connections between negative entities with positive holes [25] (in their $\sigma$ or $\pi$ nature) located on the pnictogen atoms (N, P, As and $\mathrm{Sb}$ ). 


\section{Computational details}

The structure, energy and bounded properties of the metaphosphoric acid $\left(\mathrm{HPO}_{3}\right)$ in the presence of explicit $\mathrm{H}_{2} \mathrm{O}$ molecules, as well as their hydration processes, were studied using second-order Møller-Plesset perturbation theory (MP2) [26] with Pople's $6-31+\mathrm{G}(d, p)$ basis set [27], which includes polarization functions for heavy and light atoms. In all cases, vibrational frequencies were calculated in order to verify that the structures obtained correspond to true minima or transitions states (TS). All calculations were carried out with the GAUSSIAN 09 program (revision D.01) [28]. Also, atoms in molecules (AIM) [29, 30] theory at the same computational level was applied to analyze the covalent and noncovalent interactions, using the AIMAll [31] program. Remember that the appearance of an AIM bond critical point (BCP) between centers of different monomers supports the presence of an attractive bonding interaction [29].

In order to obtain more accurate values, re-optimization at MP2/aug-cc-pVTZ [32] was performed for the stationary points. Also, in addition to the explicit $\mathrm{H}_{2} \mathrm{O}$ molecules, the presence of water solvent has been considered at such computational level by means of the polarizable continuum model (PCM) [33] using the standard parameters concerning water.

The many-body procedure $[34,35]$ was applied to trimer [Eq. (1)] and tetramer [Eq. (2)] reactants whereby the binding energy can be expressed as:

$E_{\mathrm{b}}($ trimer $)=E_{\mathrm{r}}+\sum \Delta^{2} E+\Delta^{3} E$

$E_{\mathrm{b}}($ tetramer $)=E_{\mathrm{r}}+\sum \Delta^{2} E+\sum \Delta^{3} E+\Delta^{4} E$

where $\Delta^{n} E$ is the $n$th complex term $(2=$ for dimers, $3=$ for trimers and $4=$ for tetramers), and the largest value of $n$ represents the total cooperativity in the full complex. Furthermore, $E_{r}$ is the energy that computes the monomer's deformation.

Finally, the molecular electrostatic potential (MEP) [36] on the 0.001 au electron density isosurface via the WFASAS program [37] was analyzed in the $\mathrm{HPO}_{3}$ monomer.

\section{Theoretical framework}

Deepening into the intrinsic reactivity, minima and TS were analyzed based on the conceptual DFT (CDFT) [38, 39] approach. CDFT's principles can be applied beyond the density functional theory (DFT). Thus, the development of this methodology can be used within ab initio methods as MP2. In this regard, four global properties have been analyzed in the present work: energy, reaction force, electronic chemical potential and reaction electronic flux profiles.

The intrinsic reaction coordinate (IRC) [40-42] procedure provides elementary information about the points that connect reactants, TS and products in a minimum potential energy path. All these points define the energy profile, $E$, of a chemical reaction; however, such energy profile does not give complete information about the reaction mechanism, and therefore, it is convenient to consider the reaction force, $F$ (Eq. 3), defined as the negative derivative of the total energy with respect the reaction coordinate, $\xi$ [43-46]:

$F(\xi)=-\frac{\mathrm{d} E}{\mathrm{~d} \xi}$

Also, other interesting property is the electronic chemical potential, $\mu$ (Eq. 4), which for a $N$-electronic system is defined as the derivative of the energy with respect the number of electrons when the external potential, $v(\vec{r})$, remains constant:

$\mu=\left(\frac{\mathrm{d} E}{\mathrm{~d} N}\right)_{v(\vec{r})}$

Considering that the number of electrons is a discontinuous variable, $\mu$ can be approximated in terms of the ionization potential, $I$, and the electron affinity, $A$, due to the Koopmans' theorem [47] (by extension of the Hartree-Fock methodology) and to the application of finite differences. Furthermore, applying the approximation between $A$ and $I$ with the frontier orbital HOMO and LUMO energies, $\varepsilon_{H}$ and $\varepsilon_{L}$, respectively, $\mu$ acquires the following expression (Eq. 5):

$\mu \approx-\left(\frac{A+I}{2}\right) \approx \frac{\varepsilon_{H}+\varepsilon_{L}}{2}$

As happened between $E$ and $F$, the negative derivative of $\mu$ versus $\xi$ provides the so-called reaction electronic flux, $J$ or REF (Eq. 6) [48, 49], whose interpretation results from the analogy with classical thermodynamics: Positive values of REF should be associated with spontaneous rearrangements of the electron density driven by bond strengthening or forming processes; and negative values of REF are indicating nonspontaneous rearrangements of the electron density that are mainly driven by bond weakening or breaking processes:

$J(\xi)=-\frac{\mathrm{d} \mu}{\mathrm{d} \xi}$

Based on the critical points of the energy $\left(\xi_{R}, \xi_{T S}\right.$ and $\xi_{P}$, associated with reactants, TS and products, in each case) and of the reaction force $\left(\xi_{1}\right.$ and $\left.\xi_{2}\right)$, three regions can be defined: the first one associated with the reactants, between $\xi_{R}$ and $\xi_{1}$, in which they are prepared for the reaction mainly through structural reordering; the second one, limited by $\xi_{1}$ and $\xi_{2}$, where the TS is located, which 


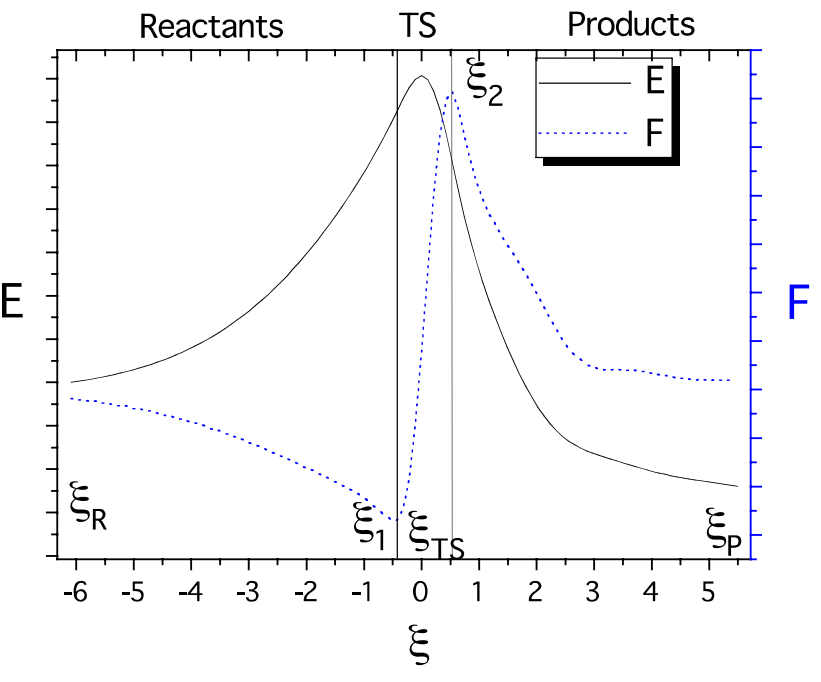

Fig. 1 Solid and dotted lines represent a generic energy, $E$, and reaction force profiles, $F$, of an elementary reaction versus the reaction coordinate, $\xi$. The location of the stationary points of the energy and force is indicated. Two vertical lines separate the reactant (left), the TS (center) and the product (right) regions

corresponds to the region where most formation and breaking of the bonds take place, this region being mainly associated with an electronic reordering; and finally, the third region, between $\xi_{2}$ and $\xi_{P}$, which is associated with structural relaxation to reach the products of the reaction [50]. Note that $\xi_{1}<\xi_{\mathrm{TS}}<\xi_{2}$ (Fig. 1).

At this point, an energy partition of the activation barrier can be made, where $W_{1}$ represents the amount of energy requires to geometrical reorganization of the system, while $W_{2}$ represents the electronic changes, both from reactants to TS (Eq. 7). Similar quantities, $W_{4}$ and $W_{3}$, can be defined for the reverse path (Eq. 8), respectively.

$E_{\overrightarrow{a c}}=W_{1}+W_{2}=-\int_{\xi_{R}}^{\xi_{T S}} F(\xi) \mathrm{d} \xi$

$W_{1}=-\int_{\xi_{R}}^{\xi_{1}} F(\xi) \mathrm{d} \xi>0$ and $W_{2}=-\int_{\xi_{1}}^{\xi_{T S}} F(\xi) \mathrm{d} \xi>0$

These properties from the CDFT approach were analyzed in the reaction mechanism of the hydration process in metaphosphoric acid at the MP2/6-31+G $(d, p)$ level.

\section{Results and discussion}

\subsection{Electrostatic properties in the $\mathrm{HPO}_{3}$ monomer}

Metaphosphoric acid monomer $\left(\mathrm{HPO}_{3}\right)$ adopts $C_{s}$ symmetry. The representation of its MEP on the 0.001 au electron

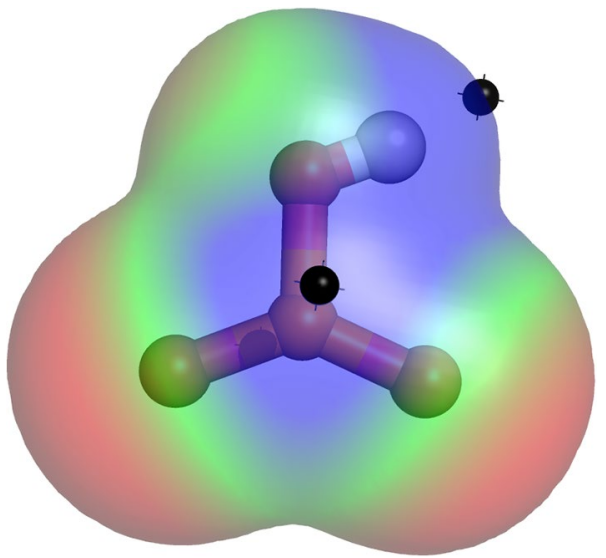

Fig. 2 Molecular electrostatic potential (MEP) on the 0.001 au electron density isosurface for the $\mathrm{HPO}_{3}$ monomer, calculated at the $\mathrm{MP} 2 / 6-31+\mathrm{G}(d, p)$ level. The red and blue colors indicate negative and positive regions, respectively, varying between -0.030 and +0.050 au. Black dots indicate the location of the ESP maxima on the contour

density isosurface, Fig. 2, shows negative (red) and positive (blue) regions, as well as the localization of three local maxima on the isosurface (black dots): two $\pi$-holes above and below the molecular plane associated with the $\mathrm{P}$ atom, and one $\sigma$-hole associated with the acidic $\mathrm{H}$ atom. The values of the potential of such maxima are 219 and $319 \mathrm{~kJ} \mathrm{~mol}^{-1}$ for the $\pi$ - and $\sigma$-holes, respectively. These points represent potential binding sites with MEP minima of partner molecules, as for instance, the $\mathrm{O}$ lone pairs in $\mathrm{H}_{2} \mathrm{O}$. In addition, the large values of these maxima indicate that the possible complexes between $\mathrm{HPO}_{3}$ and $\mathrm{H}_{2} \mathrm{O}$ should be strongly bounded. Similar behavior has been described previously in the literature in pnictogen $[8,9]$ and chalcogen [51] compounds containing $\pi$-holes.

\subsection{Hydration process}

The hydration process of $\mathrm{HPO}_{3}$ to obtain $\mathrm{H}_{3} \mathrm{PO}_{4}$ has been studied in the presence of one, two and three water molecules. These mechanisms will be referred along this section as $(a),(b)$ and $(c)$, respectively. In this section, the properties of the reactants clusters will be considered first, and then the reaction process will be taken into account.

\subsubsection{Reactant properties}

The geometry of the reactants is very much affected by the presence of water molecules (Fig. 3). The reactant of mechanism $(a)$ shows only one $\mathrm{P} \cdots \mathrm{O}$ bond between $\mathrm{HPO}_{3}$ and $\mathrm{H}_{2} \mathrm{O}$. With the introduction of a second $\mathrm{H}_{2} \mathrm{O}$ molecule in $(b)$, a six-membered pseudo-ring appears with the inclusion of the interactions between $\mathrm{H}_{2} \mathrm{O}(1)$ and $\mathrm{H}_{2} \mathrm{O}(2)$ and 
Fig. 3 From left to right, reactant, TS and product geometries for the hydration process of $\mathrm{HPO}_{3}$ in the presence of: a one; b two; and c three $\mathrm{H}_{2} \mathrm{O}$ molecules, calculated at the MP2/6$31+\mathrm{G}(d, p)$ computational level. Blue dotted lines indicate bounded interactions corroborated by AIM theory. Selected distances are shown in $\AA$
(1)

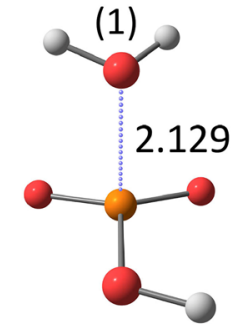

(a) $\mathrm{PO}_{3} \mathrm{H}+\mathrm{H}_{2} \mathrm{O} \rightarrow \mathrm{PO}_{4} \mathrm{H}_{3}$

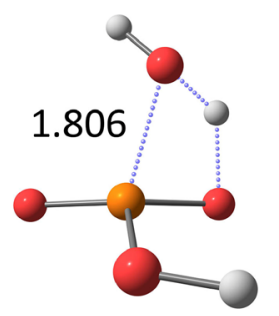

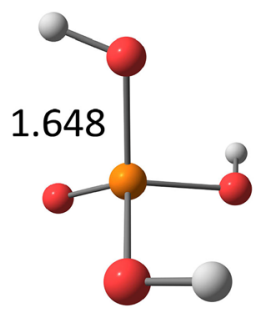

(b) $\mathrm{PO}_{3} \mathrm{H}+2 \mathrm{H}_{2} \mathrm{O} \rightarrow \mathrm{PO}_{4} \mathrm{H}_{3}+\mathrm{H}_{2} \mathrm{O}$
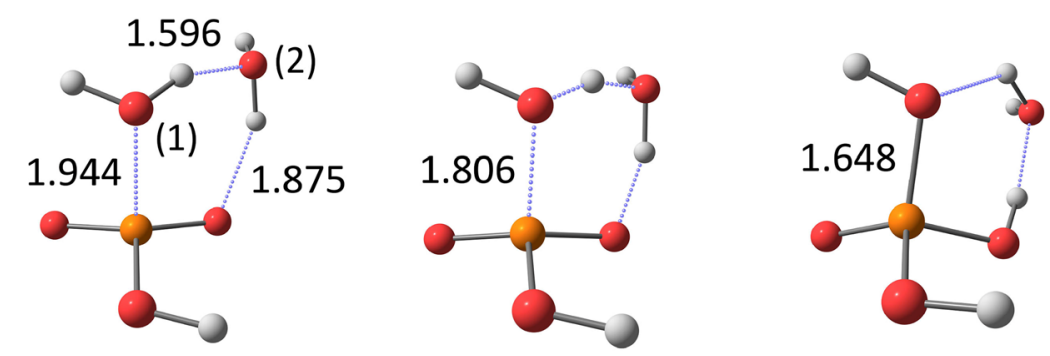

(c) $\mathrm{PO}_{3} \mathrm{H}+3 \mathrm{H}_{2} \mathrm{O} \rightarrow \mathrm{PO}_{4} \mathrm{H}_{3}+2 \mathrm{H}_{2} \mathrm{O}$
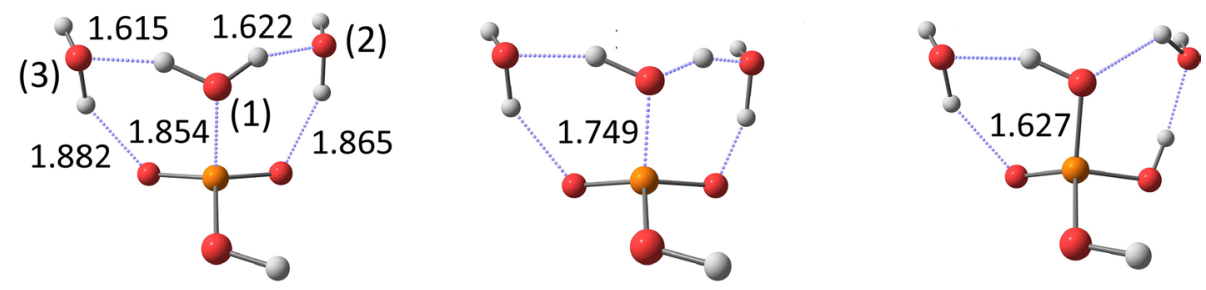

between $\mathrm{H}_{2} \mathrm{O}(2)$ and $\mathrm{HPO}_{3}$. This second case corresponds to cooperativity a well-known energy property to stabilize the system [52]. In $(c)$, this pseudo-ring remains, and by effect of $\mathrm{H}_{2} \mathrm{O}(3)$, the P...O bond decreases even further, to $1.854 \AA$. It seems that, as more number of explicit $\mathrm{H}_{2} \mathrm{O}$ molecules, more intensive is the pnictogen bond, the precursor force for the hydration of $\mathrm{HPO}_{3}$. This effect of cooperativity can be seen also in the $\mathrm{H}_{2} \mathrm{O}(1) \cdots \mathrm{H}_{2} \mathrm{O}(2)$ hydrogen bond (HB) in $(b)$ and $(c)$ : $~ 1.6 \AA$, which is practically $0.3 \AA$ shorter than for the isolated water dimer [53, 54]. The shortening of the intermolecular distances $(\mathrm{O} \cdots \mathrm{P}$ and $\mathrm{H} \cdots \mathrm{O})$ can be associated with a cooperative effect due to the formation of cyclic structures when the weak interactions are taken into account. It should be noticed that in each of the intermolecular interactions (pnictogen bond and hydrogen bonds) of each cycle, the charge transfer goes in the same direction, either clockwise or counterclockwise.

In addition, the geometry of the $\mathrm{HPO}_{3}$ molecule is affected by the number of water molecules. When isolated, it shows $C_{s}$ symmetry with the sum of the three OPO angles being exactly $360^{\circ}$. In the case of the presence of one, two and three water molecules, the sum of the OPO angles amounts to 357,354 and $351^{\circ}$, indicating the pyramidalization of this molecule.

The effect on the geometry of the reactant complex is even larger when, with the addition of the explicit water molecules, the bulk solvent is considered by means of the PCM at the MP2/aug-cc-pVTZ computational level. Thus, the P...O distances are reduced to $1.885,1.778$ and $1.746 \AA$ with one, two and three explicit water molecules, respectively.

The many-body interaction energy (MBIE) partition methodology $[34,35]$ has been applied to the reactant stationary points to gain insight on the cooperative effect due to the increasing number of water molecules present. The MBIE components detailed in Table 1 corroborate the strong noncovalent interactions that take place between $\mathrm{HPO}_{3}$ and the $\mathrm{H}_{2} \mathrm{O}$ molecule(s). In mechanism (a), all the binding energy can be associated with the pnictogen bond, amounting to $-60.4 \mathrm{~kJ} \mathrm{~mol}^{-1}$. Mechanisms $(b)$ and $(c)$ show in all cases 
Table 1 Many-body analysis $\left(\mathrm{kJ} \mathrm{mol}^{-1}\right)$ for the hydration process of $\mathrm{HPO}_{3}$ in the presence of: $(a)$ one; $(b)$ two; and $(c)$ three $\mathrm{H}_{2} \mathrm{O}$ molecules, calculated at the MP2/6-31+G(d,p) computational level

\begin{tabular}{llrrrr}
\hline Mech. & $E_{r}$ & \multicolumn{1}{c}{$\Delta^{2} E$} & $\Delta^{3} E$ & $\Delta^{4} E$ & \multicolumn{1}{l}{$E_{b}^{\mathrm{a}}$} \\
\hline (a) & 11.3 & -71.7 & - & - & $-60.4(-38.6)$ \\
$(b)$ & 35.8 & -119.2 & -52.5 & - & $-135.9(-95.7)$ \\
(c) & 58.1 & -160.2 & -107.5 & -0.7 & $-210.3(-154.6)$ \\
\hline
\end{tabular}

a Values in parentheses corrected with the basis set superposition error (BSSE) via the counterpoise procedure [55]

values of positive cooperativity of -52.5 and $-0.7 \mathrm{~kJ} \mathrm{~mol}^{-1}$, in each case. In fact, for mechanism $(c)$, the sum of the threebody terms is practically due to the interaction between the monomers which form the six-membered pseudo-ring: Values of $E_{123}$ and $E_{124}$ are -57.3 and $-58.3 \mathrm{~kJ} \mathrm{~mol}^{-1}$, where subscripts 1, 2, 3 and 4 refer to $\mathrm{HPO}_{3}, \mathrm{H}_{2} \mathrm{O}(1), \mathrm{H}_{2} \mathrm{O}(2)$ and $\mathrm{H}_{2} \mathrm{O}(3)$, respectively. The energy values corroborate the structural modifications observed in the pnictogen bonds as more explicit $\mathrm{H}_{2} \mathrm{O}$ molecules are introduced, i.e., they agree with cooperativity as stabilization force in the hydration of metaphosphoric acid. Binding energies have been also corrected with the basis set superposition error (BSSE) via the counterpoise procedure [55]. BSSE grows as the number of $\mathrm{H}_{2} \mathrm{O}$ monomers increases.

\subsubsection{Reaction}

Table 2 gathers the activation and reaction energies of such chemical reactions, as well as the $W_{1}$ and $W_{2}$ quantities. The first important characteristic concerns the activation barriers, $67.0 \mathrm{~kJ} \mathrm{~mol}^{-1}$ for $(a)$, with a significant decrease when successive explicit $\mathrm{H}_{2} \mathrm{O}$ molecules are included: 12.8 and $17.4 \mathrm{~kJ} \mathrm{~mol}^{-1}$, for $(b)$ and $(c)$, respectively. This reduction can be explained attending to the role that the explicit $\mathrm{H}_{2} \mathrm{O}$ molecules play. In mechanism $(a), \mathrm{H}_{2} \mathrm{O}$ acts as reagent, forming a four-membered ring angularly stressed in the reaction site of the TS (Fig. 3). When a second $\mathrm{H}_{2} \mathrm{O}$ comes into play, it exerts the role of a catalyst, incrementing the ring size by formation of a six-membered ring with less angular stress and diminished steric repulsions, promoting also the proton transfer. This fact entails the diminution of $\sim 55 \mathrm{~kJ} \mathrm{~mol}^{-1}$ between $(a)$ and $(b)$. The introduction of a third $\mathrm{H}_{2} \mathrm{O}$ molecule, which is placed not in the pseudoring of the reaction site, but standing between neighboring $\mathrm{P}=\mathrm{O}$ moieties, slightly destabilizes the system, and the activation barrier increases $\sim 5 \mathrm{~kJ} \mathrm{~mol}^{-1}$ between $(b)$ and (c). The $W_{1}$ and $W_{2}$ quantities present similar values in percentage for all cases; however, mechanism $(b)$ has a slightly higher activation energy due to electronic reordering $\left(W_{2}\right)$ : 24 versus $17 \%$ and $19 \%$ in $(a)$ and $(c)$, respectively, being the part associated with the geometric rearrangement $\left(W_{1}\right)$ always higher than $W_{2}$ in all cases. This catalytic effect has also been observed in the mutarotation process of sugars $[56,57]$ and in the reaction of formation of hemiacetals [58]. The reaction energies are always negative, that is, associated values of spontaneous processes, being smaller as more explicit $\mathrm{H}_{2} \mathrm{O}$ molecules are introduced.

The activation energies optimized at MP2/aug-cc-pVTZ computational level and in PCM-water to emulate implicitly the bulk water reveal that: (1) For mechanism (a), it is $70.7 \mathrm{~kJ} \mathrm{~mol}^{-1}$, which is $3.7 \mathrm{~kJ} \mathrm{~mol}^{-1}$ larger than the same process in gas phase; and (2) mechanisms $(b)$ and $(c)$ present very low values, 0.1 and $4.5 \mathrm{~kJ} \mathrm{~mol}^{-1}$. They are, specially the one obtained in $(b)$, dramatically low, indicating that, once $\mathrm{HPO}_{3}$ is solvated by the water molecules, it is very close to the hydrated system, as can be seen in the $\mathrm{P}$... O distances in the reactants showing values of 1.778 and $1.746 \AA$, for mechanisms $(b)$ and $(c)$, respectively. Also, the Gibbs free reaction energy at $298 \mathrm{~K}$ between the phosphoric acid and the isolated $\mathrm{HPO}_{3}+n \mathrm{H}_{2} \mathrm{O}$ molecules account to -125.9 , -133.1 and $-152.7 \mathrm{~kJ} \mathrm{~mol}^{-1}$ for mechanisms $(a),(b)$ and $(c)$, respectively. These results are in reasonable agreement with the experimental value of $134 \pm 8 \mathrm{~kJ} \mathrm{~mol}^{-1}$ [2].

Finally, Fig. 4 reports the energy, reaction force, electronic chemical potential and REF profiles. Values of reaction force at $\xi_{1}$ are consistent with the activation barriers obtained. Thus, $\left|F\left(\xi_{1}\right)\right|$ are around 40, 10 and $15 \mathrm{~kJ} \mathrm{~mol}^{-1} \mathrm{amu}^{-1 / 2} \mathrm{bohr}^{-1}$ for $(a),(b)$ and (c), respectively, from which the effect of the explicit $\mathrm{H}_{2} \mathrm{O}$ molecules can be derived and corroborated, as either reagent or catalysts, in their role in decreasing the angular stress in the reaction site before reaching the TS. More interesting are the $\mu$ and REF profiles, from which the following

Table 2 Activation $\left(E_{a c}\right)$ and reaction $\left(E_{R}\right)$ energies in $\mathrm{kJ} \mathrm{mol}^{-1}$ for the hydration process of $\mathrm{HPO}_{3}$ in the presence of: $(a)$ one; $(b)$ two; and $(c)$ three $\mathrm{H}_{2} \mathrm{O}$ molecules. Also, $W_{1}$ and $W_{2}$ quantities, in percentage, are shown

\begin{tabular}{lllllrr}
\hline & $E_{a c}{ }^{\mathrm{a}}$ & $E_{R}^{\mathrm{a}}$ & $W_{1}^{\mathrm{a}}$ & $W_{2}^{\mathrm{a}}$ & $E_{a c}^{\mathrm{b}}$ & \multicolumn{1}{c}{$\Delta G_{R}^{298}$} \\
\hline$(a)$ & 67.0 & -108.6 & 83 & 17 & 70.7 & -125.9 \\
$(b)$ & 12.8 & -78.4 & 76 & 24 & 0.1 & -133.1 \\
$(c)$ & 17.4 & -63.5 & 81 & 19 & 4.5 & -152.7 \\
\hline
\end{tabular}

${ }^{\text {a }}$ Values at MP2/6-31+G( $\left.d, p\right)$ computational level

b Values at MP2/aug-cc-pVTZ computational level 
(a) $\mathrm{HPO}_{3}+\mathrm{H}_{2} \mathrm{O} \rightarrow \mathrm{H}_{3} \mathrm{PO}_{4}$
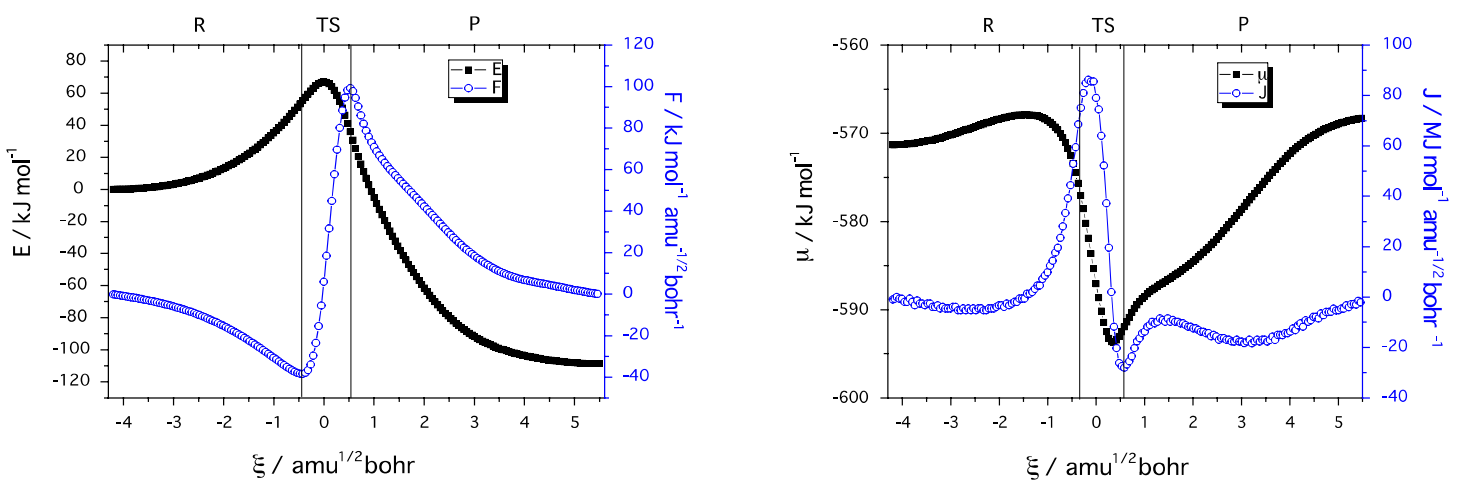

(b) $\mathrm{HPO}_{3}+2 \mathrm{H}_{2} \mathrm{O} \rightarrow \mathrm{H}_{3} \mathrm{PO}_{4}+\mathrm{H}_{2} \mathrm{O}$
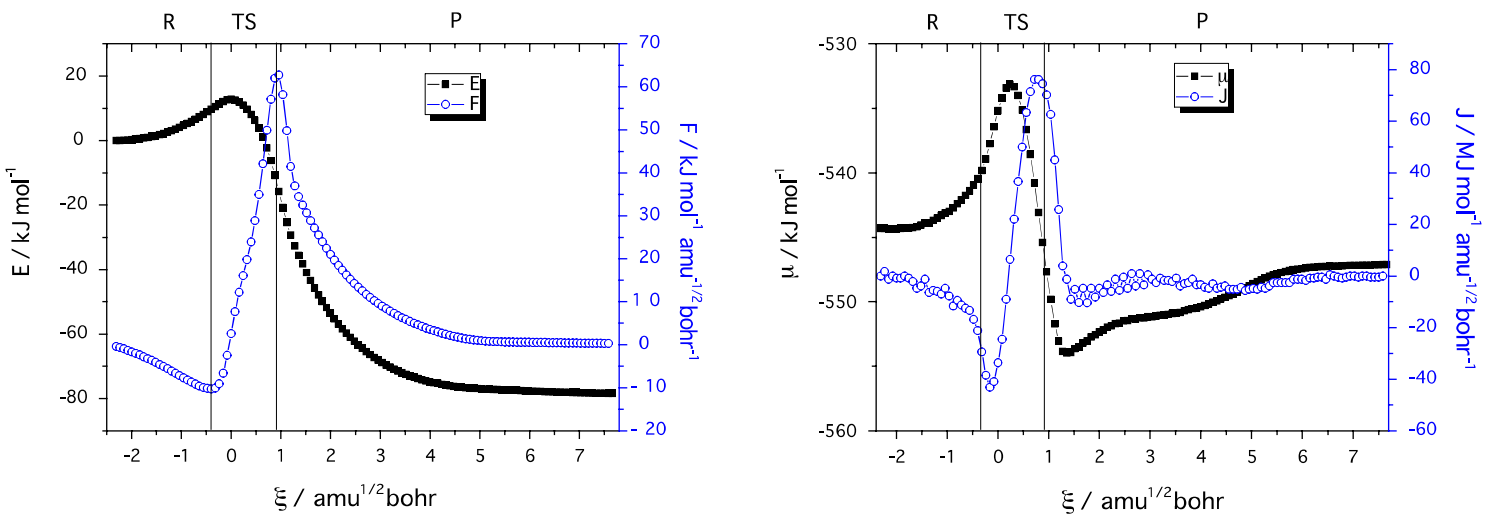

(c) $\mathrm{HPO}_{3}+3 \mathrm{H}_{2} \mathrm{O} \rightarrow \mathrm{H}_{3} \mathrm{PO}_{4}+2 \mathrm{H}_{2} \mathrm{O}$

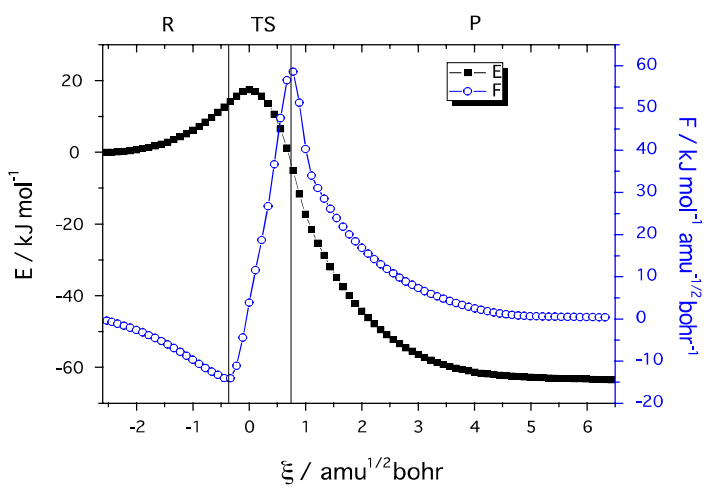

Fig. 4 Energy (black squares) in $\mathrm{kJ} \mathrm{mol}^{-1}$ and reaction force (blue circles) in $\mathrm{kJ} \mathrm{mol}^{-1} \mathrm{amu}^{-1 / 2} \mathrm{bohr}^{-1}$ profiles versus the reaction coordinate in $\mathrm{amu}^{1 / 2}$ bohr (left). Electronic chemical potential (black squares) in $\mathrm{kJ} \mathrm{mol}^{-1}$ and REF (blue circles) in $\mathrm{kJ} \mathrm{mol}^{-1}$

conclusion can be drawn: (1) For the three mechanisms studied, the principal reactive changes occur in the TS zone; (2) reactants and products are stable species due do the zero-flux regime since and until the chemical reaction proceeds; and (3) mechanism (a) differs from mechanisms (b) and $(c)$ in the behavior of $J\left(\xi_{1}\right)$ and $J\left(\xi_{2}\right)$. In this regard,

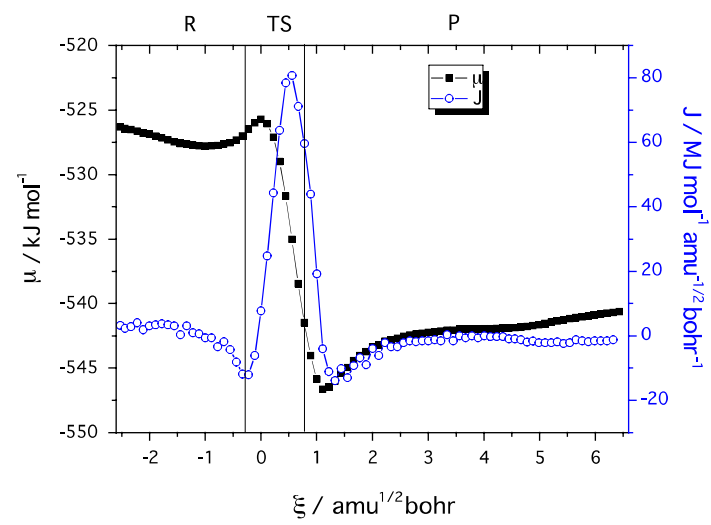

$\mathrm{amu}^{-1 / 2} \mathrm{bohr}^{-1}$ profiles versus the reaction coordinate in $\mathrm{amu} \mathrm{u}^{1 / 2} \mathrm{bohr}$ (right), for the hydration process of $\mathrm{HPO}_{3}$ in the presence of: $\mathbf{a}$ one; $\mathbf{b}$ two; and $\mathbf{c}$ three $\mathrm{H}_{2} \mathrm{O}$ molecules, calculated at the MP2/6-31+ $\mathrm{G}(d, p)$ computational level

REF in (a) presents one maximum and one minimum, while in $(b)$ and $(c)$, the contrary occurs, i.e., one minimum followed by one maximum. What is the origin of this different behavior? A one-step reaction could have many elementary sub-processes. In our case, two events occur: on the one hand, the formation of a covalent $\mathrm{P}-\mathrm{O}$ bond, and 
Fig. 5 Representation of the: (a) electron density, $\rho$; (b) its Laplacian, $\nabla^{2} \rho$; and (c) total energy $\mathrm{H}$, at the BCP, all in au versus the interatomic $\mathrm{P} \cdots \mathrm{O}$ distances, in $\AA$

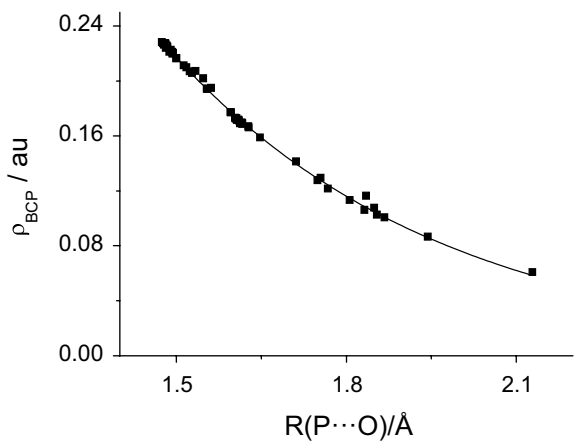

(a)

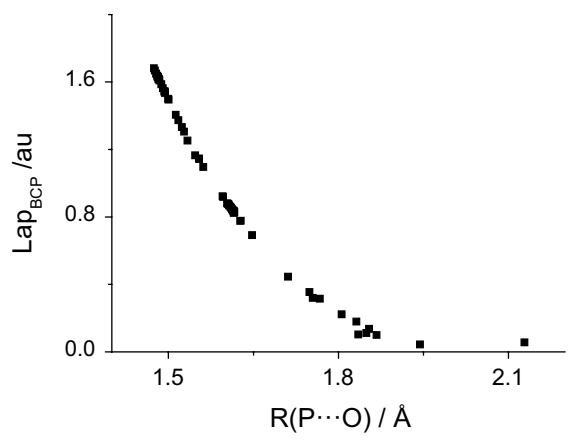

(b)

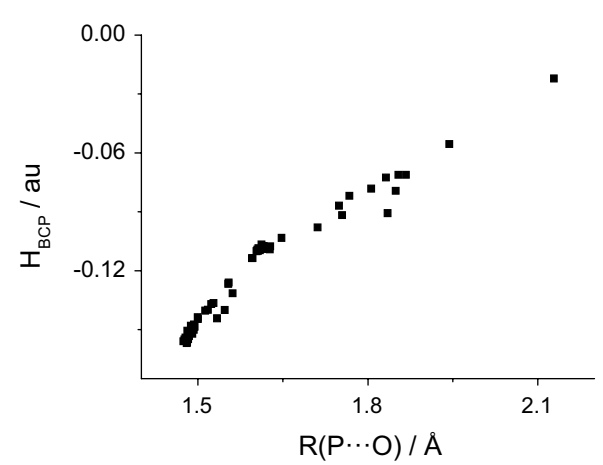

(c)

on the other, a proton transfer for the formation of a covalent $\mathrm{O}-\mathrm{H}$ bond. These events take place simultaneously, but with more or less synchronicity. It is evident that in mechanism (a), first occurs the formation of the $\mathrm{P}-\mathrm{O}$ bond, and subsequently, the proton transfer. For this reason, REF is in positive regimen around $J\left(\xi_{1}\right)$, spontaneous rearrangements driven by bond strengthening or forming processes, and in negative regimen around $J\left(\xi_{2}\right)$, nonspontaneous rearrangements driven by bond weakening or breaking processes. The contrary order happens in mechanisms $(b)$ and $(c)$.

The electron density properties at the $\mathrm{P}-\mathrm{O}$ bond critical points $(\mathrm{BCP})$ in the stationary points of the reaction have been plotted versus the corresponding interatomic distances. The $\mathrm{P}-\mathrm{O}$ distance values range between 2.13 and $1.47 \AA$. The electron density shows an exponential dependency with the distance as has been shown for other bonds $[59,60]$. The behavior of the Laplacian is more surprising being positive in all the range of distances studied. It shows large values for the shortest $\mathrm{P}-\mathrm{O}$ distances and decreases as the distance increases. Several authors have reported the positive Laplacian for covalent bonds [61] and more recently we have shown that the $\mathrm{P}-\mathrm{N}$ bond have a similar behavior to the $\mathrm{P}-\mathrm{O}$ one [62]. The values of the total energy at the BCP are negative for all the cases indicating a significant covalent contribution for the interactions that as expected increases (more negative values of $\mathrm{H}$ ) for the shortest distances [63] (Fig. 5).

\section{Conclusions}

A theoretical study of the hydration reaction of metaphosphoric acid to yield phosphoric acid has been carried out at the MP2/6-31+G(d,p) and MP2/aug-ccpVTZ computational levels. Up to three explicit water molecules have been considered, and the effect of the bulk solvent has been taken into account by means of the PCM method. The reactant structure shows an important dependence on the number of explicit water molecules, as well as on the bulk solvent effect by inclusion of the PCM. An important cooperativity effect is observed in the $\mathrm{HPO}_{3}$ complexes with two and three water molecules. The barriers observed for these systems when PCM is included show a very small values for the transformation, and the calculated reaction energy between the phosphoric acid and the isolated $\mathrm{HPO}_{3}+n \mathrm{H}_{2} \mathrm{O}$ molecules is between 126 and $153 \mathrm{~kJ} \mathrm{~mol}^{-1}$, depending on the model considered, which is in reasonable agreement with the experimental value of $134 \pm 8 \mathrm{~kJ} \mathrm{~mol}^{-1}$. The analysis of the IRC of the reactions indicates a decrease in the angular stress in the reaction site before reaching the TS as more explicit water molecules are taken into account. The analysis of the REF shows that for the three mechanisms studied, the principal reactive changes occur in the TS zone, while reactants and products remain in a zero-flux regime. 
Acknowledgments This work has been supported by the CTQ2012-35513-C02-02 (MINECO) and Fotocarbon S2013/MIT2841 (Comunidad Autónoma de Madrid) Projects. Also, LMA thanks the MICINN for a Ph.D. Grant (number BES-2010-031225). Computer, storage and other resources from the CTI (CSIC) are gratefully acknowledged.

Conflict of interest The authors declare no competing financial interest.

\section{References}

1. Wilkinson A, McNaught AD (1997) Compendium of chemical terminology. The "Gold Book", 2nd edn. IUPAC, Oxford, UK

2. Guthrie JP (1977) J Am Chem Soc 99:3991-4001

3. Gevrey S, Luna A, Haldys V, Tortajada J, Morizur J-P (1998) J Chem Phys 108:2458-2465

4. Hu C-H, Brinck T (1999) J Phys Chem A 103:5379-5386

5. Loncke PG, Berti PJ (2006) J Am Chem Soc 128:6132-6140

6. Iché-Tarrat N, Barthelat J-C, Rinaldi D, Vigroux A (2005) J Phys Chem B 109:22570-22580

7. Davies JE, Doltsinis NL, Kirby AJ, Roussev CD, Sprik M (2002) J Am Chem Soc 124:6594-6599

8. Alkorta I, Elguero J, Del Bene JE (2013) J Phys Chem A 117:10497-10503

9. Bauzá A, Ramis R, Frontera A (2014) J Phys Chem A 118:2827-2834

10. Del Bene JE, Alkorta I, Sánchez-Sanz G, Elguero J (2011) Chem Phys Lett 512:184-187

11. Scheiner S (2011) J Chem Phys 134:094315

12. Zahn S, Frank R, Hey-Hawkins E, Kirchner B (2011) Chem Eur J 17:6034-6038

13. Adhikari U, Scheiner S (2012) Chem Phys Lett 532:31-35

14. Alkorta I, Sánchez-Sanz G, Elguero J, Del Bene JE (2012) J Chem Theory Comput 8:2320-2327

15. Alkorta I, Sánchez-Sanz G, Elguero J, Del Bene JE (2012) J Phys Chem A 117:183-191

16. Scheiner S (2012) Acc Chem Res 46:280-288

17. Solimannejad M, Ramezani V, Trujillo C, Alkorta I, SánchezSanz G, Elguero J (2012) J Phys Chem A 116:5199-5206

18. Alkorta I, Elguero J, Del Bene JE (2013) J Phys Chem A 117:4981-4987

19. Sánchez-Sanz G, Alkorta I, Trujillo C, Elguero J (2013) ChemPhysChem 14:1656-1665

20. Sánchez-Sanz G, Trujillo C, Solimannejad M, Alkorta I, Elguero J (2013) Phys Chem Chem Phys 15:14310-14318

21. Scheiner S (2013) CrystEngComm 15:3119-3124

22. Azofra LM, Alkorta I, Elguero J (2014) ChemPhysChem 15:3663-3670

23. Bauzá A, Mooibroek TJ, Frontera A (2015) Chem Commun 51:1491-1493

24. Hobza P, Müller-Dethlefs K (2009) Non-Covalent Interactions. The Royal Society of Chemistry, Cambridge

25. Murray J, Lane P, Clark T, Riley K, Politzer P (2012) J Mol Model 18:541-548

26. Møller C, Plesset MS (1934) Phys Rev 46:618-622

27. Frisch MJ, Pople JA, Binkley JS (1984) J Chem Phys 80:3265-3269

28. Frisch MJ, Trucks GW, Schlegel HB, Scuseria GE, Robb MA, Cheeseman JR, Scalmani G, Barone V, Mennucci B, Petersson GA, Nakatsuji H, Caricato M, Li X, Hratchian HP, Izmaylov AF, Bloino J, Zheng G, Sonnenberg JL, Hada M, Ehara M, Toyota K, Fukuda R, Hasegawa J, Ishida M, Nakajima T, Honda Y, Kitao
O, Nakai H, Vreven T, Montgomery J, J. A., Peralta JE, Ogliaro F, Bearpark M, Heyd JJ, Brothers E, Kudin KN, Staroverov VN, Kobayashi R, Normand J, Raghavachari K, Rendell A, Burant JC, Iyengar SS, Tomasi J, Cossi M, Rega N, Millam NJ, Klene M, Knox JE, Cross JB, Bakken V, Adamo C, Jaramillo J, Gomperts R, Stratmann RE, Yazyev O, Austin AJ, Cammi R, Pomelli C, Ochterski JW, Martin RL, Morokuma K, Zakrzewski VG, Voth GA, Salvador P, Dannenberg JJ, Dapprich S, Daniels AD, Farkas Ö, Foresman JB, Ortiz JV, Cioslowski J, Fox DJ, GAUSSIAN09, Revision D.01, Wallingford CT, 2009

29. Bader RFW (1990) Atoms in Molecules: A Quantum Theory. Clarendon Press, Oxford

30. Popelier PLA (2000) Atoms In Molecules. An introduction, Prentice Hall, Harlow, UK

31. Keith TA, AIMAll (Version 13.11.04), TK Gristmill Software, 2013

32. Del Bene JE (1993) J Phys Chem 97:107-110

33. Tomasi J, Mennucci B, Cammi R (2005) Chem Rev 105:2999-3094

34. Xantheas SS, Dunning TH (1993) J Chem Phys 99:8774-8792

35. Xantheas SS (1994) J Chem Phys 100:7523-7534

36. Murray JS, Politzer P (2011) WIREs Comput Mol Sci 1:153-163

37. Bulat F, Toro-Labbé A, Brinck T, Murray J, Politzer P (2010) J Mol Model 16:1679-1691

38. Parr RG, Yang W (1994) Density-Functional Theory of Atoms and Molecules. Oxford University Press, Oxford

39. Geerlings P, De Proft F, Langenaeker W (2003) Chem Rev 103:1793-1874

40. Fukui K (1970) J Phys Chem 74:4161-4163

41. Fukui K (1981) Acc Chem Res 14:363-368

42. Gonzalez C, Schlegel HB (1990) J Phys Chem 94:5523-5527

43. Politzer P, Toro-Labbé A, Gutiérrez-Oliva S, Herrera B, Jaque P, Concha M, Murray J (2005) J Chem Sci 117:467-472

44. Toro-Labbé A, Gutiérrez-Oliva S, Concha MC, Murray JS, Politzer P (2004) J Chem Phys 121:4570-4576

45. Azofra LM, Alkorta I, Elguero J, Toro-Labbé A (2012) J Phys Chem A 116:8250-8259

46. Azofra LM, Alkorta I, Toro-Labbé A, Elguero J (2013) Phys Chem Chem Phys 15:14026-14036

47. Koopmans T (1934) Physica 1:104-113

48. Echegaray E, Toro-Labbé A (2008) J Phys Chem A 112:11801-11807

49. Giri S, Echegaray E, Ayers PW, Nuñez AS, Lund F, Toro-Labbé A (2012) J Phys Chem A 116:10015-10026

50. Jaque P, Toro-Labbé A (2000) J Phys Chem A 104:995-1003

51. Azofra LM, Alkorta I, Scheiner S (2014) Phys Chem Chem Phys 16:18974-18981

52. Mó O, Yáñez M, Elguero J (1992) J Chem Phys 97:6628-6638

53. Reimers JR, Watts RO, Klein ML (1982) Chem Phys 64:95-114

54. Lane JR (2012) J Chem Theory Comput 9:316-323

55. Boys SF, Bernardi F (1970) Mol Phys 19:553-566

56. Alkorta I, Popelier PLA (2011) Carbohydr Res 346:2933-2939

57. Azofra LM, Alkorta I, Elguero J, Popelier PLA (2012) Carbohydr Res 358:96-105

58. Azofra LM, Alkorta I, Elguero J (2012) J Phys Org Chem 25:1286-1292

59. Sánchez-Sanz G, Alkorta I, Elguero J (2011) Mol Phys 109:2543-2552

60. Azofra LM, Scheiner S (2014) J Phys Chem A 118:3835-3845

61. Cremer D, Kraka E (1984) Croat Chem Acta 57:1259-1281

62. Del Bene JE, Alkorta I, Elguero J (2014) J Phys Chem A 118:10144-10154

63. Rozas I, Alkorta I, Elguero J (2000) J Am Chem Soc 122:11154-11161 